\title{
Displacement and Assimilation: Reframing Disporic Nuances in JhumpaLahiri's Interpreter of Maladies
}

\author{
SulekhaVarma, AntimaThapliyal
}

\begin{abstract}
The research paper aims at reframing the diasporic nuances such asalienation due to displacement, and assimilation as portrayed in JhumpaLahiri'sInterpreter of Maladies. This literary work discusses various changes and features of immigrants. The study of Diaspora, generally, describes the nature of memory, exile, nostalgia, alienation, and crises of identity. It surveys the two points; Assimilation and Alienation which are prominently raised in Diaspora writing. The present paper states about the collocation or nearness of past and present. The Cultural frames of references are implicated in traditions, rituals and specially the characters. They put an effort to make the cultures and traditions alive through the works. It also highlights the places; homeland as well as established country. The present study focuses on the widespread characteristics of Diaspora like discrimination, nostalgia, survival, cultural and traditional changes and identity. The study also touches upon novels and short stories that go along with the common traits or features of diasporic literature.
\end{abstract}

Keywords: diaspora, alienation, assimilation, cultural change, cultural perspective, homeland, identity,

\section{INTRODUCTION}

JhumpaLahiri is a famous and renowned American writer. She is also chosen the prizewinner of the 29th award of PAN/Malamud to her best short story. Interpreter of Maladies is a witty and excellent collection of short stories, (1999). Lahiri also won the Pulitzer Prize for her fiction in 2000. Her first novel, The Namesake (2003) added one more feather to her cap.Lahiri won several other prizes for her literary excellence. The intellectual works of Lahiri are especially representative of an amalgamation of her minute observation of moral, culture as well as psychological factuality, which is closely related to the outstanding literary qualities which convert her writings into flexible, elegant, ironic and compassion.The stories of Lahiri mirror the delimmaof theIndian immigrants, who have been trapped in the mid of the two traditions and cultures. The former is inherited while the next isaccepted. They have encountered it but do not necessarily assimilate. (JhumpaLahiri) The writer has shown theunbroken bondbetween the two; the old world of India and the mesmerizing and advanced America throughthe characters of the stories.The Interpreter of Maladiesreveals her admirable grasp of presenting two different cultures in one country, it is really a marvelous and grand way to express the in-depth feelings and emotions.

Revised Manuscript Received on August 10, 2019.

SulekhaVarma, Assistant Professor, Graphic Era Hill University,

Dehradun, India.

AntimaThapliyal, Assistant Professor, Graphic Era Deemed University, Dehradun, India.
JhumpaLahiri has won the prestigious Pulitzer Prize inyear 2000 for her first excellent collection of short story Interpreter of Maladies. Lahiri puts an effort to describe or interpret the maladies of Indian immigrants through this collection by uncovering their disporic delicacy. The witty and excellentwritings of Jhumpa Lahiri portray Bengali immigrant family, who has settled down on foreign land, leaving their own homeland. She is such a writer, who has herself experienced the life of foreign land, and she is sharing that experience through her writings. She has deep understanding and awareness of Diaspora and its related terms likediscrepancy, difference, multiple possibilities of alienation and assimilation,that all are automatically going on in their minds in different ways.

\section{DISPLACEMENT, ALIENATION IN LAHIRI'SFICTION}

The term 'Exile' refers to a condition wherein a person is kept away from their home, but it cannot be said that the sense of exile is the proof of a disconnected and displaced life. This is also noticed profoundly that if there is a topographical deracination, the condition of exilein various cases have appeared bothmental as well as physical. But this term is much related to the psychological factor for the immigrants have deep rooted memories about their previous life in India, where they have their own home and cherished memories. The Indian immigrants in the West countries have experienced a physical deracination but in today's advanced and globalized universe the immigrants are not taken as other, it is also observed mostly that the huge population of the immigrants migratethemselves, it is their earn and inclination to switch from their own land to a strange land, so there is very less or no reason for them to experience the sense of alienation. (JhumpaLahiri) The present era is the world of advanced and global village, which enhances the emotion and feelof be a part of native place, which defines the psychological condition of the mind and it has great importance. But for those, who came to foreign land unwillingly because of some of their helplessness, the psychological disposition of such immigrants captures the genuine picture of their alienation on the strange land.

The short story as A Temporary Matter describes the strangeness or alienation and seclusion which the Indian immigrants encounter in foreign countries. 
The marriage tie is regarded to be the holy between two persons throughout their life in India but it is shattered into pieces just because of highpressure of new challenges and demands, which is encountered by the second generation immigrants on the foreign land.

The present story focuses on life of Shukumar and Shobha, who are living their life in Boston, leaving their own land. There is a temporary issue of the electricity cut off, and it will go on for an hour, continuous five days in their house. This is a prime time during these five days thatShukumar and Shobhaboth have come near to each other after a long period of busy schedule of their daily life. They use to play indoor games as telling one mysterious event or storyrelated to their personal life to each other in darkness. Shukumarhas welcomed this power cut for an hour, for the light of nearness comes in their relation just because of darkness and the differences and variation disappeared from their relations. They were free for they could share their inner and in-depth feelings and emotions openly to each other, without any hesitation in that darkness. They were enjoying and living that moment fully up to its brim, which is endowed by the electricity power cut. While in the veryearly morning of the fifth day of the week, An announcement has been made that there wouldn't be electricity power cut any more furtheras its line has put backas usual.As Shukumarhad heard this announcement, it made him little bit disappointed. But as he had been habitual of living in darkness and he felt easy and comfortable in it, so he finds a solution for this he uses to keep the room dark by switching off the lights from 8 'o clock sharp and waits for the game as he uses to play earlier.Shobhasswitches on the light after they finished their dinnerand she also announces that she hasdecided to stay alone, away from him and she has also got one for herself.Actually shehas bored of the same game so now she wants some secluded and personal space for herself. As Shukumar hears this statement from Shobha, He becomes upset. In fact he has made his mind up to disclose the mystery to her, which he hides from her. The secret is related to the baby of Shobha, He reveals to her that she has given birth to a dead baby boy. The revelation of this secret has added a great trouble to her, mentally and physically at that very time.

The present story portrays lack of communication and untuned marriage life of second generation immigrants' couple which results the state of strangeness for botbShobha and Shukumar. They areIndian immigrants, fromBengali origin. These two have met four years back atthe time of lecture hall in Cambridge,on the same place a group of Bengali poets weredelivering the presentations. They decides to get married to each other but they have lost their only baby boy at the time of its delivery in the same duration of three years of their marriage. This tragic incident proves a very tough time as well as a great shock to Shobha and it has resultedlack of communication, misunderstanding, distance between the couple.Shobhagives extra time to her work and remains busy and excessive engaged in additional assignments to divert her mind from her past life, while Shukumar reduces himself into loneliness and inactivity gradually. Both the couple become experts; maintaining distances from each other and later on they find out that there was nothing between them to share through communication. So they used to observe silence in the presence of each other. In this disturbed and tensed state of connubial relations, they get the notice of electricity powercut. This gives them a chance to spend few momentstogether. The couple starts to share their past. They share everything with each other whatever they don't share since their marriage, with the help of newly started communication, the destroyed and torn relationship begins to get restored again. The exchange of conversation and confession improveShukumar and Shobha's weak relationship.

In the present story, Shobhahas represented herself as a typical American lady.Evenfalling in the cogmire of difficulties, she gets good relations withShukumar, even then she decides to stay alone because she gets bore from the repeated way of living each day. This attitude of Shobhamirrors a clash between the doublecultures. But as she comes across the mystery about her dead baby boy, she also getsrealized thatShukumar still loves a lot to her. Inspite of her raring and education in western world, we get a glimpse of impression that stillshe has admired Indian principles. Shukumar, the hero of the story also felt that he is away from guilt, as he rips a picture of a lady from a book and remains it hidden inside his book for several weeks.

After just the tragic event,Shoba and Shukumarboth are also displaced psychologically. It has not taken too long time but within a period of few months, they converted themselves in such a way that they started to avoid and ignore each other. This event has changed the married life of both entirely. The marriage institution, which linked both of them together, was diminishing the value of it on a foreign land. The main tragic flaw of these couples is that inspiteof so many difficulties in their life; these displaced couples do not get any appropriate and valuable cooperation from anyone like their family members, friends, and acquainted people on the strange land, in this condition, the sense of alienation becomesworst.

The short story 'When Mr. Pirzada comes to have dinner, ituncovers pages of seclusionof a single person, who has left his own native place to do research in America. He faces uneasiness and discomfort, while the battle begins emerging over East Pakistan.The current story begets all thedifferent aspects of homesickness as well as a step into a personal world of memories and reminiscence.This story captures an image of Pirzada, who tolerates the pangs ofdetachment from his affectionate and dear family members, who live their life in his native place Dacca. His longing for his native home, can be observed minutely, when he is caught; takingdinner with the parents Lilia.

When Lilia refreshes her memories, peeping into the window of past that how her parents and Pirzada have observed the creation of Bangladesh in the year1971.The situation was extremely violent and brutal,the people became wild, and they were killing each other mercilessly on T.V. She also shares the feelings of present and past deracination with a very heavy heart. It was the inner feeling which was connected to their past consequences of the

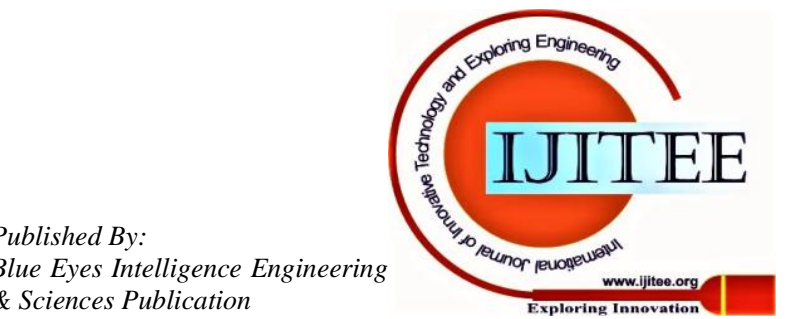


world, sothe parents of Lilia use to search a fellow citizen by the help of University Directory in each new semester. This sort of identification, affinity and similarities of ideas frame a groundto lessen the feelings of alienation that usually holdthe head and heart of the Indian immigrants.

The story 'Interpreter of Maladies', is the description of a couple, who are Indian immigrants, Mr. Das,Mrs. Mina his wife and their three children Ronny, Bobby, and Tina. The setting of the story has taken place in Puri, where the coupleand their children are inside ataxi with a travelerguide to have a view of well-known and renowned sun temple at Konark. As they were with Mr. Kapasi,they have continued their conversation with him throughout the journey on the way, the couple finds out that Mr. Kapasi's occupation as a guide is a part time job inspite of this profession he is also working in a doctor's clinic as an interpreter. Mr. Kapasi does not take hisoccupation as an interpreter a special one, whileon the other hand Mrs. Das has got his occupation something very exciting andadmirable.Kapasi was stunned to listen these words of Mrs. Das for even his own wife hasnever appreciatedand respected his profession as an interpreter. When Mrs. Das starts enjoying his company and shows her interest in him, Mr. Kapasialso begins to show the same romantic bondage to her. He is highly fascinated and advances further, when the couple put an offer to click the photos with them.

Mrs. Das takes the postal address from Mr. Kapasi to send the photos to him from America. The most catastrophic condition comes before Mr. Kapasi, when sheturns the pages of her past life before him in the car that Bobby is the son of her husband's Punjabi-Indian friend. Actually Mrs. Das tries to hide this secret but it makes her restless and uneasy. The story takes a turn and it becomes evocative where Mrs. Das earns that Mr. Kapasishould interpret her malady, which transforms her into a very emotionalhomesick lady duringeviction. The part of the story, which has a turn of extra-marital relation and to hide this relation, has affected Mrs. Das psychologically. It sometimes resultsin her mental alienation and variance. As sheexpressesthatshe is feeling heavy and disturbed psychologically and emotionally.

In this story, Mr. Kapasihas not given any remedy and treatment to the melody of Mrs. Das. All that he can do just he asks her. Is this the pain you feel? Or Is this, the guilt, you accept? The silence of Mrs. Das on these questions destroys the day dream of Mr. Kapasi. It is also an end of their unexpected, meaningless and wired relations. The melody, Mrs Das goes through, is an instance ofcultural conflict, which is also going on psychologically. The question arisesthat as they are living in America, where it is common to have an extramarital affair. It is not a serious issue there. So which thing forces her to conceal this secret relation from her husband? It can be said that it is just the provision ofvalues and morals that she has alreadycollected from her native society and culture, which remains in her psychology and it proves thatshe follows them unconsciously.

The story 'Mrs. Sen's' explains the utmost seclusion and anguish of a Bengali female character on the foreign land. In 'Mrs. Sen's', the title of this story indicates the place of passion in her life. Mrs. Sen is a lady of thirty years. She does not have a baby yet. So she passes her most of the time in the residence of University, on the other hand her husband Mr. Sen, is a Professor of Mathematics. He uses to remainbusy all the time in his academicactivities. Mr. Sengives a piece of advises to his wife that she should learn driving. She should step out from the residence whenever she is free, while it is not an easy task for a conventional Indian housewife to learn drivingeffortlessly. In due course of time Mrs. Senworks as babysitter in her house. Eliot, who is an eleven years child, he comes to her house daily when his school is off ashis mother is working far away from her residence. Even his father works two thousand miles away. She scarcely shows affection and love for her own son. Afterfinishing the dinner at home, she leaves the remaining undo household work for Eliot to complete.Eliot becomes a substitute son to Mrs. Sen.Both enjoy each others' company, she always offers something edible to him. They enjoy the relationship of a son and mother.

Eliot is an introvert boy and he has no objection about a pizza which his mother uses to feed himevery night for she is too tired to prepare anything for him. He accepts this happily as a normalthing while Mrs. Sen needs to assure herself that she does not miss her mother. Mrs. Sen's inability to leave behind the past and Eliot's passive acknowledgment of his lifestyle both are opposite to each other. Eliot has gone too far from his mother for she is not having time for her own son. She was quite opposite to Mrs, Sen. While MrsSentreats Eliot with utmost love and affection so he came in a very close contact with her.

Mrs.Senlearns driving and she also makes an effort to maintain a sort of friendship with mother of Eliot. But she is not much interested in this type of relationship. Mrs. Senand Eliot's mother both are outsiders on the foreign land. But Eliot' mother pretends to be the native of the land. She treats Mrs.Sen in a formal and professional manner, while Mrs. Senputs an effort to tie Eliot's mother in a healthy and affectionate bond. She entertains and greets her politely, while Eliot's mother was quite opposite to her in behavior. It can be stated that the feeling of external or alienation becomes harshamongthe Indian immigrants. This type situation is encountered by those people, who don't belong to that land. Thenative of the country, avoid having contacts with those, who are varied and different from them in so many ways. The plight of these people, who have uprooted from their own country and their switch to a foreign land and culture both give them utmost pain. While the statement like mind your own businessthis sort of attitude of the native people contribute to the feeling of displacement and alienation which influence Mrs. Sen'salife up to the heights. The setting of the story 'A Real Durwan' has taken place in Calcutta. It defines exile and alienation. The prominent character of thisstoryis Boori Ma, who is a refugee from East Pakistan, now she is established in Calcutta in a depressed condition. There are two things together factuality and fiction, whichshe has stated about herprevious journey of life. Now she hasparted from his family and house. 
AsBoori Ma states that her life was a royal and glorious one in East Pakistan. She used to take bath in fragrant water with flower's petals and scent. It is just a turn of adverse fate that she has to work as an unsanctioned guard in a building of Calcutta. At this time she is living on charity and kindness of the residents, she protects the building from doubtful strangers. The people are highly thankful for her cooperation. The people show sympathy towards her. It gives her immense pleasure for some times but she is unable to forget that she is living a life of an exile.

The story 'The Treatment of BibiHaldar' also dealswith the displacement and alienation. It shows how BibiHaldar likeBoori Ma of 'A Real Durwan' she becomes a victim of alienation and external at her own house, society and family. This sad and painful story is portrayed in Calcutta. It also shows the clash between simplicity and shrewdness. BibiHaldar was an orphan, since childhood and it was diagnosed that she is suffering from a hysterical illness of epilepsy. She was living with her relative in Calcutta. She was given a storage room on the roof that proves her pathetic condition, Actually she lives in a very inconvenience place even it is hard to stand straight in that room. It is the last wish of her life to get married. Each day she earns for a man, who will offer herto get married. She is always curious and excited to listen the full fledged description of other wedded ladies life. Many times she was disturbed and tensedabout her unaccomplished desires and wishes. The doctors, who examine her even they declare only marriage will be helpful to regain her good health. While on the other hand Mr. and Mrs. Haldardon't show any sort of concern to Bibi's marriage. Theymake conclusion about the expenditure on wedding. When the neighbors insisted a lot about her marriage, so Mr. Haldar gives an advertisement for her marriage in the newspaper.

The advertisement of marriage speaks a lot about the plight of a female, who is not fit and suitable for marriage. There is another aspect of the life of a lady that marriage is very essential part of her life. Marriage is the last destination of every woman. Even this advertisement does not prove a fruitful one, as it was expected. In the pregnancy of Mrs. Haldar, Bibi is treated in a very cheap and inferior manner for she does not belong to a high caste. Mrs. Haldar is afraid of her for she thinks that she can create ill omen to her family, soshe avoids her in best possible manner to avoid any sort ofharm to her kid. Mrs. Haldardelivers a baby girl. Her daughter suffers from ill health for five days. Mrs. Haldar again comes under the previous influence of conservativeness and she blamed Bibi for the sickness of her daughter. At the end Mr. Haldarshuts his cosmetic shop and decides to leave the place with his family.Bibiis left secluded with Rs. 300/- In a sense thatBibi becomesan immigrant, who is displaced in her own house. She lives just because of the cooperation of her helpful neighbors.

The story 'Sexy' the conviction of displacement and disconnection is given an advanced twist. This story interprets such immigrants, who have not experienced disconnectivity after leaving their native place for they are not having any traces belongingness over there. While it will be felt by those who belong to their own home, and they are having maximum number of reminiscences on their native land.Lahiri, clarifies it byan instance of an American lady, she has experienced it all personally, she has left her own land and establishesher residence on a foreign land. Actually the novelist wishes to draw the picture of her stories as they are written, keeping in mind the multicultural nature of the people and society that has started to accept the people, who leave their land and comes to a foreign land as they are similar somewhere even then they belong to varied cultures. The story describes Miranda's character, who falls in love with a married Bengali man. He leaves her both emotionally worn out and alienated without consideration her emotional and psychological condition.

The story 'The Third and Final Continent' interprets novelist's feelings for native home.The first generation Indian immigrants brings alteration in themselves. In fact, after living in America for long thirty years, it reflects how the immigrants can handle alienation in a very effective manner.They adopt the foreign land and requirement for assimilation. They try to gain emotional firmness and stability. They have taken citizenship of American. Even though theyvisit Calcutta each year, and bring so many things from there like pajams and Darjeeling tea, now they have made their mind to spend their remaining years there on the foreign land. They have realized the signs of resemblance between the two Bengali and American life. Just because of this frankness of their nature provides them strength and power to admire and adorn America as their own home.

The Indian immigrantwriters havediscovered the sense of displacement, a persistent subject matter both the aspects arevisible in the literary works of exile. The picture of the immigrants is more pathetic and touching by going throughnot only the geographical dislocation but also a sense of socio-cultural displacement.

\section{CHARACTERS' NOSTALGIA AS WELL AS ASSIMILATION}

The characters of Lahiriexpress nostalgia for theirown nativecountry.it is a sign of seclusion and displacement in a strange territory.Lahiri'sliterary works bringsout emotional clashes between the first and the second generationseffectively. The children, who took birth on the foreign land, they don't want to join with the altering view of the world of their parents. Even they don't want to identify their roots through an apparent appreciation of food andscenery.Theinclinationis much for America, they have created their own world there and they don't want to think about any other place except that. Most prominently, it is also noticed in her works that new immigrants of the first generationcautiously reconstruct a sense of home within their domestic province by covering themselves with the reminiscences of their previous life. Mrs. Senaffectionately passes her life by preparing varied Bengali dishes,now it is transparent that the concept of 'home' is expended beyond National, International and territorial borders, including psychological and emotional touch. 
In the story 'When Mr. Pirzada Came to Dine', Lahiridefines nostalgia as well as varied frames of belongingness. Mr. Pirzada's entry allows Lilia, the child narrator to know the value her parents profoundly. The story explains about Lilia's enhancing admiration to her dear parents' nostalgia and separation. She as a secondgeneration American, she knows well to make balance between both the cultures Bengali and American, one is inherited while the other is adopted respectively, which highlights her cultural assimilation. (JhumpaLahiri)As Lahiri has portrayed that Lilia's parents are not comfortable in their adopted home. Lilia's mother was proud of that Lilia is going have a secure and comfortable life with valuable education and excellent opportunities for career. In spite of leading a luxurious and comfortable life in foreign country, even they look back their past, which they have left in their own country.

Most of the stories of Lahiri have differentiated the sort of nostalgia, which is experienced by variousimmigrants. There is explicitly emotional touch andinterest for Indian food or music. In her case as she has taken birth in America even then the origin is Indian. There is an invisible understanding of their cultural attachment. But pangs of nostalgic fervor are less in them for the immigrants want to settle in their re-living, without forgetting their previous way of living. The second generation characters are fully adopted with the territory, they have taken birth.

In the story 'This Blessed House', the person finds out with the passing of time that his wife is still a stranger to him for he can not sharehis cultural values to her. Actually he is nostalgic about the conservative as well as traditional sort of marriage, as his parents may have enjoyed in their time period. He feels a continuous requirement to put a reminder every time to his wife about Indian inheritance for he is closely and profoundly attached to his origin and values.

The story 'The Third and Final Continent', explains the plightof the immigrants, who arrive to the foreign land but have profoundly attached to their own native land. She mirrors the seclusion, loneliness and puzzling experience of the new arrived immigrants, who are living their life on the foreign land in a great confusion. They are trapped there on their own land. Everything was easy and acquainted while in their current situation everything is unknown and living their life in isolation. The feeling of nostalgia rolls automatically in their memories. There is a longing to nostalgic emotionsfor shared language, culture, and tradition. There is also invisible fear among the immigrants which disappears with the passing of time.In spite of permanent settlement on the foreign land, even if they are financially stable and established in relationships like marriage or the connection between parents and their children. Theprotagonists of Lahiri seem tostand at the crossroads. And after having all type of satisfaction, they are lacking something and the result of this is that they always face isolation or two options to select one.

Lahiri'sfamilies of short stories are found mostly smaller ones. The members of the families belong to the acculturated second and third generation. The characters of stories put in the diasporic space, which belong to different stages of cultural assimilation. While Mrs. Sen in the story 'Mrs. Sen's' is a newcomer, who is closely connected to

Bengali Indian culture. Shobha and Shukumar in 'A Temporary Matter' or Mr. And Mrs. Das in 'Interpreter of Maladies' are portrayed as Americans and they have also adopted a hybrid culture. Shobha, for instance, has close American friend Gillian. The eating habits of the couple, sharing of household duties these all are pointing their assimilation. In the story, 'When Mr. Pirzada Came to Dine' Lilia is born and reared in a foreign culture and society so she does not believe to her parents' cultural and traditional practice.

The cultural assimilation as well as bridging two cultures together isbest portrayed in Lahiri'slast story 'The Third and Final Continent'. It also reflectsparallelism and balance between thetwo worlds. It not onlyhighlights the financial crises and seclusion, facedby the Indian immigrants, who come from India but also explorestheir strong determination to winin all phases of life whether that is financial, political or social. They believe that they can make harmony between the two cultures after stepping in new life in America. It should be notable point in the geniuswritings of Lahirithat the main purpose of the novelist is to visualize that although this has to pay a heavy price that's sacrifice their own land. And their success because of the immigrant's ability and capability create, innovate and make balance and harmony in varied phases of their life. The story is an indepth study of the narrator's 'tone. He is an aged Indian person, who turns back to his previous life and recalls his time of Struggle andstrife to survive. He also recalls his friends and companions of Bengalis.

The narrator and his wife both have planned to pass their entire remaining life in America, as it is safe and secure to be there. His wife also tries to adjust in her advanced phase of life. She also come across not to put the end of the sari over her head. She also avoids to cry at nights for her parents for it would be useless to so for she has to cultivate the habit of living on the foreign the land.The immigrants also learned the trick of living on the foreign and it will be possible when they explore other Bengalis rid of their seclusion and unknown society. While both Mr. Pirzada and Mrs. Sen are intended toassimilate in their life.Lilia's parents have been habitual of living double life easily, identifying their previous life, rituals, traditions and food habits etc, but they don't avoid their present life, and they equally enjoy and participate in the current life of American traditions.Lahiri gives instances of varied aspects of nostalgia and assimilation.

JhumpaLahiridiscovesthe theme of the difficultiesand plight of the immigrants on the foreign land in a very excellent manner. There is a great clash between the two generations and cultures. Even then the immigrants are very much expert to make balance and assimilate their living on the foreign land.

\section{REFERENCE}

1. Bala, Suman (Ed.). JhumpaLahiri: The Master Storyteller (A Critical Response to "Interpreter of Maladies"). New Delhi: Khosla Publishing House, 2002. 
2. Dhawan, R. K. ed. Writers of the Indian Diaspora. New Delhi: PrestigeBooks, 2001.

3. Jha, Gaurishankar. Ed. Current Perspectives in Indian English Literature. New Delhi: Atlantic Publishers \& Distributors. 2006 Print.

4. Kaur, Tejinder. Portrayal of Diaspora Experiences in JhumpaLahiri's Interpreter of Maladies, Indian English Literature. Vol.2 Ed NaikerBasavraj. New Delhi: Atlantic Publishers and Distributors, 2002, pp192.

5. Kaushal, Anupama. The Literature of Indian Diaspora (ed. T.S Anand) New Delhi, Creative Books, 2010, p 92.

6. Lahiri, Jhumpa. Interpreter of Maladies. New Delhi: Harper Collins, 1999.

7. Mathur, O .P . The Modern Indian English Fiction. New Delhi: Abhinav Publications, 1993.

8. Mishra, Vijay. 'New Lamps for Old: Diasporas Migrancy Border Interrogating Post- Colonialism: Theory, Text, and Context. Eds. Harish Trivedi and MeenakshiMukherjee, IIAS, Shimla, 1996, p $67-$ 68.

9. Nityanandam, Indira. JhumpaLahiri: The Tale of the Diaspora. New Delhi: Creative Books, 2005.

10. Prasad, Amarnath, and John Peter Joseph. "Indian Writing in English: Critical Ruminations. New Delhi: Sarup\& Sons., 2006

11. Shukla- Kaushik, Abha. Diaspora, and Cross-cultural Identity: A Study of JhumpaLahiri's Fictional Works, Women Writers of Indian Diaspora Ed. Silky Kumar Anand, Creative Books, New Delhi, 2010, pp 58.

12. Singh, ManjitInder. Contemporary Diasporic Literature: Writing History, Culture, Self. Delhi, Pencraft International, 2007, p 41-42. 